\title{
Development and evaluation of virtual refrigerant mass flow sensors for fault detection and diagnostics
}

\author{
Woohyun Kim ${ }^{\mathrm{a}^{*}}$, James E. Braun ${ }^{\mathrm{b}}$ \\ a. Pacific Northwest National Laboratory, Richland, WA, 99352, USA; \\ b. Herrick Laboratory, Purdue University, Mechanical Engineering, \\ West Lafayette, IN, 47906, USA \\ * Corresponding author; Tel.: +1 765494 9157. E-mail: jbraun@purdue.edu (J.E.Braun)
}

\begin{abstract}
Refrigerant mass flow rate is an important measurement for monitoring equipment performance and enabling fault detection and diagnostics. This paper presents and evaluates three different virtual refrigerant mass flow (VRMF) sensors that use mathematical models to estimate flow rate using low cost measurements. The first model uses a compressor map that relates refrigerant flow rate to measurements of condensing and evaporating saturation temperature, and to compressor inlet temperature measurements. The second model uses an energy-balance method on the compressor that uses the compressor power consumption. The third model is developed using an empirical correlation for an electronic expansion valve (EEV) based on an orifice equation. The three VRMFs are shown to work well in estimating refrigerant mass flow rate for various systems under fault-free conditions with less than 5\% RMS error. The combination of the three VRMFs can be utilized to detect and diagnose when the compressor and/or expansion device are not providing the expected flow.
\end{abstract}

Keywords:

Virtual sensor; Refrigerant mass flow rate; fault detection and diagnostics; Compressor; Expansion device; Performance monitoring 


\section{Nomenclature}

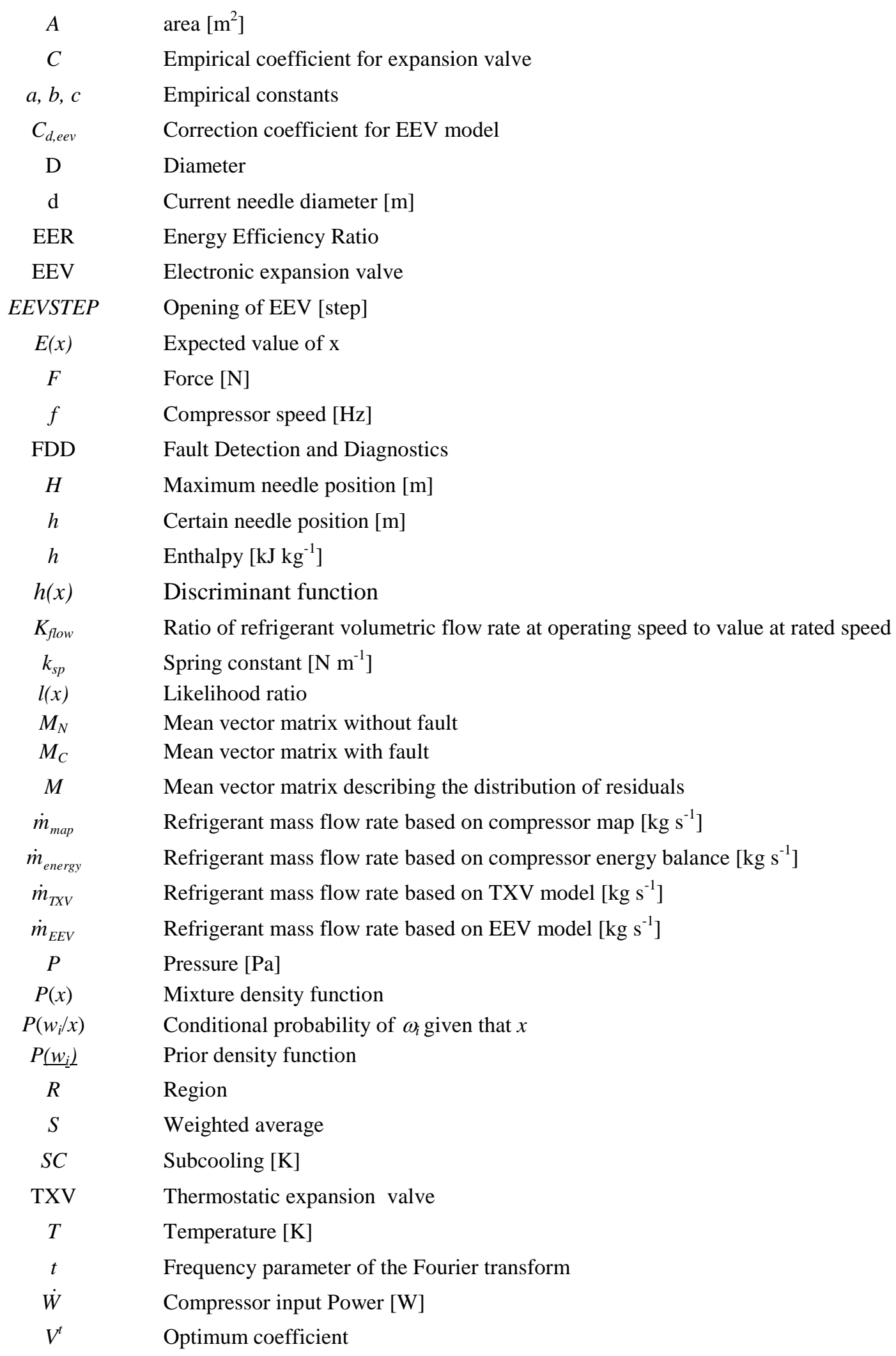




\section{Subscripts}

\begin{tabular}{cl} 
actual & Actual \\
$b$ & Bulb \\
$C$ & Current \\
$c$ & Condenser \\
cri & Critical \\
current & Current \\
diaph & Diaphragm \\
dis & Discharge \\
$e$ & Evaporator \\
$f$ & Liquid \\
$g$ & Gas \\
max & Maximum \\
measured & Measurement \\
min & Minimum \\
$N$ & Normal \\
orifice & Orifice \\
pin & Needle \\
pred & Estimation \\
rated & Rated condition \\
sat & Saturation \\
$s p$ & Spring \\
sp, cl & Closed spring \\
suc & Suction \\
TXV & Thermostatic expansion valve \\
& \\
\hline
\end{tabular}

\section{Greek}

$\begin{array}{cl}\rho & \text { Density }\left[\mathrm{kg} \mathrm{m}^{-3}\right] \\ \alpha_{\text {loss }} & \text { Compressor heat loss ratio } \\ \delta & \text { Spring deflection }[\mathrm{m}] \\ \mu_{i} & \text { Mean of residual } \\ \Sigma_{1} & \text { Covariance matrix without fault conditions }\end{array}$




\author{
Covariance matrix with fault conditions \\ Bayesian Classification error \\ Mahalanobis distance \\ Standard deviations \\ Class $i$ \\ Threshold for given distribution \\ Standard normal random variable
}

\title{
1. Introduction
}

Space heating, ventilation and air conditioning (HVAC) account for $40 \%$ of residential primary energy use, and for $30 \%$ of primary energy use in commercial buildings (Energy Efficiency and Renewable Energy, 2008). Over half of all conditioned floor space in the U.S. incorporates packaged HVAC equipment in their system design (Brodrick, 2000). The study conducted by Messenger (2008) indicates unitary air conditioners typically do not achieve rated efficiency because of improper installation or lack of servicing in the field. This paper suggested that service and replacement programs can yield energy savings on the order of 30 to 50\%. The other study from ADM (2009) evaluated 109 units in the field and found that 89 had fault conditions, with 31 having two or more faults. The average Energy Efficient Ratio (EER) for the units increased from 6.6 before servicing to 7.0 after servicing, an average increase of $6.1 \%$. Another investigation (Katipamula and Brambley, 2005) suggested that faults or non-optimal control can cause the malfunction of equipment or performance degradation from 15 to $50 \%$. Automated diagnostics has the potential to address these field performance problems and produce significant energy savings.

Even though various fault detection and diagnostic (FDD) studies (Rossi and Braun 1997; Li and Braun 2007; Kim et al., 2009) have been carried out for air conditioner and heat pump systems with fixed speed compressors and fixed orifice expansion (FXO) valves, FDD research for systems with variable speed compressors and electronic expansion valves (EEV) has been limited. The use of variable speed compressors is common in Asia and has recently started to make in-roads within the U.S. market for commercial and residential air conditioners. In this paper, virtual sensors for variable speed compressors and EEVs were developed to estimate mass flow rate using inexpensive temperature sensors and embedded models.

Refrigerant mass flow rate is an important measurement for monitoring HVAC systems and enabling Automated Fault Detection and Diagnostics (AFDD) to save energy and extend equipment life. Three different virtual refrigerant mass flow (VRMF) sensors were developed and evaluated in this study that use mathematical models to estimate flow rate using low cost measurements. The three approaches use: 1) a compressor map for refrigerant mass flow rate that uses inlet pressure and temperature and outlet pressure as inputs; 2) an energy-balance method employs a virtual sensor for power consumption based on a compressor map; 3) semi-empirical correlations for EEV and thermostatic expansion valves (TXV) that are based on an orifice equation. The models were trained and tested using data obtained from earlier laboratory studies. The application of the virtual sensors for diagnosing low compressor flow (e.g., leaky compressor valve) faults and insensitivity to other faults are also demonstrated using the available data. The long-term operation of a compressor may cause discharge and suction valve leakage due to valve wear and tear. The low compressor flow fault can be identified by comparing predictions of 

in this study, the VRMFs could also be used to identify a fault expansion valve.

\section{System descriptions and test conditions}

Laboratory test data from a variety of sources were used to develop and evaluate VRMF sensors. Table 1 gives specifications for equipment where data were obtained through laboratory testing. The systems include a water-to-water heat pump with a variable speed compressor, a residential air split system, and light commercial packaged systems with fixed and variable speed compressors. The systems used either a TXV or EEV as an expansion device and R-22, R-410A, or R-404A as a refrigerant. Some of the units included low-side accumulators.

Table 2 presents the range of operating test conditions for each unit, including the range of refrigerant flow rates encountered. The laboratory test data were obtained with variations in both indoor and ambient temperature. Two of three systems were tested with different condenser and evaporator water or air flow rates, which could represent faults associated with a dirty air filter or coil fouling. All of the systems except for system II were tested at different refrigerant charge levels to simulate improper charge service and refrigerant leakage. Systems I, II, and III included simulated low compressor flow (e.g., compressor valve leakage) faults where a portion of the discharge flow from the compressor was bypassed to the low-pressure side of the system. The percentage of refrigerant mass flow given in Table 2 represents the ratio of the flow delivered to the expansion device to the normal compressor flow (i.e., flow without bypass) at those operating conditions. Similarly, the percentage indoor or outdoor air/water flows were referenced to the normal values. System II differed from the other units in that it was a laboratory setup for testing EEVs over a very wide range of refrigerant flows. Two different valves (B0B and B1F in the Table 1) were tested with two different refrigerants (R-410A and R-404A in Table 2). The $\mathrm{B} 1 \mathrm{~F}$ valve has a rated refrigerant flow (also cooling capacity and associated air/water flow) that is three times higher than that for the B0B valve. System III also included fault testing for a liquid line restriction (additional pressure drop increase through liquid line) and the presence of non-condensable gas (injection of nitrogen gas into the system). In general, only normal operating (i.e., no-fault) data were used to learn parameters of the VRMF sensors, whereas all of the data were used for assessing VRMF sensor performance.

Table 1 System descriptions for laboratory test data

\begin{tabular}{|c|c|c|c|c|c|c|c|}
\hline \multicolumn{2}{|r|}{ System } & $\begin{array}{r}\text { Size } \\
(\mathrm{kW})\end{array}$ & Refrigerant & Compressor & Expansion Device & Accumulator & System Type \\
\hline I & $\begin{array}{c}\text { (Kim and Kim, } \\
2005)\end{array}$ & 3 & R-22 & $\begin{array}{l}\text { Variable speed } \\
\text { compressor }\end{array}$ & EEV & No & \multirow{3}{*}{$\begin{array}{l}\text { Water to } \\
\text { Water }\end{array}$} \\
\hline \multirow{2}{*}{ II } & \multirow{2}{*}{ (Bach et al., 2012) } & \multirow{2}{*}{7.0} & R-410A & \multirow{3}{*}{$\begin{array}{l}\text { Fixed speed } \\
\text { compressors }\end{array}$} & EEV (B0B) & \multirow{2}{*}{ Yes } & \\
\hline & & & $\mathrm{R}-404 \mathrm{~A}$ & & EEV (B1F) & & \\
\hline III & (Kim et al, 2008) & 8.8 & $\mathrm{R}-410 \mathrm{~A}$ & & TXV & Yes & Air Split Type \\
\hline
\end{tabular}

Table 2 Test conditions for laboratory testing data

\begin{tabular}{|c|c|c|c|c|c|c|c|c|c|}
\hline \multirow{3}{*}{ System } & \multicolumn{2}{|c|}{$\begin{array}{c}\text { Indoor } \\
\text { air/water } \\
\text { temperature }\end{array}$} & \multirow{2}{*}{$\begin{array}{c}\text { Outdoor } \\
\text { air/water } \\
\text { temperature }\end{array}$} & \multirow{2}{*}{$\begin{array}{l}\text { Percentage } \\
\text { of refrigerant } \\
\text { mass flow } \\
\text { rate }\end{array}$} & \multirow{2}{*}{$\begin{array}{l}\text { Indoor } \\
\text { air/water } \\
\text { flow rate }\end{array}$} & \multirow{2}{*}{$\begin{array}{l}\text { Outdoor } \\
\text { air/water } \\
\text { flow rate }\end{array}$} & \multirow{2}{*}{$\begin{array}{l}\text { Refrigerant } \\
\text { charge } \\
\text { amount }\end{array}$} & \multirow{2}{*}{$\begin{array}{l}\text { Percentage } \\
\text { of normal } \\
\text { pressure } \\
\text { drop through } \\
\text { TXV } \\
\end{array}$} & \multirow{2}{*}{$\begin{array}{l}\text { Percentage } \\
\text { of injected } \\
\text { non- } \\
\text { condensable } \\
\text { gas mass }\end{array}$} \\
\hline & $\begin{array}{l}\text { Dry } \\
\text { bulb }\end{array}$ & $\begin{array}{l}\text { Wet } \\
\text { bulb }\end{array}$ & & & & & & & \\
\hline & ${ }^{\circ} \mathrm{C}$ & ${ }^{\circ} \mathrm{C}$ & ${ }^{\circ} \mathrm{C}$ & $\%$ & $\%$ & $\%$ & $\%$ & $\%$ & $\%$ \\
\hline
\end{tabular}




\section{VRMF sensor I based on a compressor flow map}

\subsection{Development of VRMF sensor I for constant speed compressors}

A compressor map is used to estimate refrigerant mass flow rate using input measurements of inlet and outlet pressure. Based on ANSI/ARI 540-1999, refrigerant mass flow rate for a fixed speed compressor can be represented using a 10-coefficient polynomial equation for a specified amount of superheat. The map at the specified superheat is typically corrected using the ratio of the compressor suction density at the actual superheat to the density at the tested superheat. Based on the ARI model form, the VRMF Sensor I for a fixed speed compressor is determined using equation 1.

$$
\dot{m}_{\text {map }}=\rho_{\text {suc }} \cdot\left(a_{0}+a_{1} T_{c}+a_{2} T_{c}+a_{3} T_{e}^{2}+a_{4} T_{e}^{2}+a_{5} T_{c} \cdot T_{c}+a_{6} T_{e}^{3}+a_{7} T_{e}^{3}+a_{8} T_{e}^{2} \cdot T_{c}+a_{9} T_{c}^{2} \cdot T_{e}\right)
$$

where $\dot{m}_{\text {map }}$ is the estimated refrigerant mass flow rate, the a's are empirical coefficients, $T_{e}$ is evaporating saturation temperature, $T_{c}$ is condensing saturation temperature, and $\rho_{s u c}$ is the density at the suction (inlet) of the compressor.

\subsection{Development of VRMF sensor I for variable speed compressors}

Variable speed compressors are one of the most energy efficient methods to regulate capacity for heat pumps and air conditioners because they minimize on/off cycling (Qureshi and Tassou, 1996 and Aprea et al., 2004). Despite the expanded application of variable speed compressors, there are only a few modeling approaches for compressor performance that have been published (Navarro-Esbri et al., 2007; Park et al., 2001; Browne and Bansal, 2002). Manufacturers typically provide several map-based models at different frequencies for variable speed compressors. The compressor performance for other operating frequencies can be calculated using interpolation and extrapolation. However, this type of modeling approach may not work well over a wide range of operating conditions. To overcome this limitation, empirical functional equations were developed and validated that provide accurate estimates of mass flow rate for variable speed compressors.

\subsubsection{Refrigerant volumetric flow rate at rated frequency}

The virtual sensor adopts a two-step model where the maximum volumetric flow is correlated in terms of the evaporation and condensing temperature at the rated compressor speed and then is corrected for the actual operating speed. The rated volumetric flow rate is determined using the second-order polynomial equations given in equation 2 . The condensing and evaporating temperatures can be measured on return bends within the heat exchangers. The flow rate is expressed as volumetric flow because it can be readily converted to a mass flow rate using the suction density regardless of the inlet superheat even though the testing was performed at a fixed superheat as shown in equation 2 , 
where $\dot{V}_{\text {rated }}, \dot{m}_{\text {rated }}$, and $\rho_{\text {suc,rated }}$ are the compressor volumetric flow rate, mass flow rate, and suction density at the rated frequency and superheat; the c's is empirical coefficients; $T_{e}$ is evaporating saturation temperature; and $T_{c}$ is condensing saturation temperature.

\subsubsection{Correction modeling at different frequencies}

A volumetric flow rate ratio $\left(K_{\text {flow }}\right)$ for converting the rated volumetric flow rate to volumetric flow rate at any operating speed and superheat is defined in equation 3 ,

$$
K_{\text {flow }}=\frac{\dot{m}_{\text {measured }}}{\left(\dot{V}_{\text {rated }} \cdot \rho_{\text {suc,rated }}\right)}
$$

where $\dot{m}_{\text {measured }}$ is the compressor mass flow rate measurement at any operating frequency and inlet superheat.

Figure 1 shows trends in $K_{\text {flow }}$ in terms of evaporation temperature and compressor frequency for system I with different condensing temperatures. $K_{\text {flow }}$ is relatively independent of evaporating and condensing temperature and depends primarily on compressor frequency. An empirical model for this volumetric flow rate ratio is expressed with a second-order function of frequency as shown in equation 4. The coefficients can be estimated based on regression analysis using experimental data at different frequencies,

$$
K_{\text {flow }}=\left(a_{1} \cdot\left(f-f_{\text {rated }}\right)^{2}+a_{2} \cdot\left(f-f_{\text {rated }}\right)+a_{3}\right)
$$

where the a's are empirical coefficients, $f$ is operating frequency, and $f_{\text {rated }}$ is the rated compressor frequency.

The virtual sensors for estimating refrigerant mass flow rate and compressor input power use the products of the rated output from equation 2 and the correction factor from equation 4 with the result presented in equation 5. The accuracy of the mass flow rate prediction is less under conditions where the compressor inlet superheat is zero, corresponding to a two-phase mixture. However, the other virtual mass flow rate sensors can be applied under these conditions.

$$
\dot{m}_{\text {map }}=\left(\dot{V}_{\text {rated }} \cdot \rho_{\text {suc, rated }}\right) \cdot K_{\text {flow }}=\left(\dot{V}_{\text {rated }} \cdot \rho_{\text {suc, rated }}\right) \cdot\left(a_{1} \cdot\left(f-f_{\text {rated }}\right)^{2}+a_{2} \cdot\left(f-f_{\text {rated }}\right)+a_{3}\right)
$$


Figure 1. Volumetric flow rate ratio in terms of evaporator saturation temperature for different compressor speeds (system I)

\subsection{Performance of VRMF sensor I}

This section presents performance of the VRMF Sensor I compared to measured mass flow rate. Table 3 provides a list of faults that were used in evaluating the performance of the VRMF sensors and defines the nomenclature used in the subsequent figures. To evaluate performance of the VRMF sensor, the predicted ratio of refrigerant mass flow rate to rated flow is compared to the value determined using measurements. The VRMF model I was individually trained using only the normal data for each system but used to predict flow rates for all of the fault tests.

Table 3 Fault list

\begin{tabular}{|c|c|c|c|c|c|c|}
\hline Normal & Comp Fault & Cond Fault & Evap Fault & Liquid Fault & Charge fault & NonCond Fault \\
\hline No fault & $\begin{array}{c}\text { Low } \\
\text { compressor } \\
\text { flow fault }\end{array}$ & $\begin{array}{c}\text { Condenser } \\
\text { fouling fault }\end{array}$ & $\begin{array}{c}\text { Evaporator } \\
\text { fouling fault }\end{array}$ & $\begin{array}{c}\text { Liquid line } \\
\text { restriction fault }\end{array}$ & $\begin{array}{c}\text { Refrigerant } \\
\text { charge fault }\end{array}$ & $\begin{array}{c}\text { Non-condensable } \\
\text { fault }\end{array}$ \\
\hline
\end{tabular}

Figure 2 shows the performance of VRMF sensor I for system III with a fixed speed compressor under no fault and various faulty conditions. The RMS error is generally less than $2 \%$ for normal operation and with a variety of faults except for low compressor flow (e.g., valve leakage). For the range of compressor leakage conditions considered, the RMS error for the VRMF sensor I was 19\%. As the severity of the compressor fault level is increased, the error in the estimated value also increases. As a result, differences between refrigerant flows determined using VRMF sensor I and other VRMF sensors can be used to diagnose a fault associated with the compressor not delivering the proper refrigerant flow. 
Figure 2. Performance of VRMF sensor based on fixed speed compressor map for system III under no fault and fault conditions (RMS of sensor errors shown for each fault type)

Figure 3 shows the performance of VRMF sensor I for system I with a variable speed compressor under no fault and various fault conditions. Although the VRMF sensor I was trained using only no-fault data, it accurately estimates mass flow rate for faulty conditions over the range of operating frequencies, except for the low compressor flow (e.g., valve leakage) fault. The RMS errors for VRMF sensor I were less than 3\% for condenser fouling, refrigerant charge, and evaporator fouling conditions, respectively. However, VRMF sensor I predictions were about $16 \%$ higher than measurements for the range of compressor fault conditions considered, with the errors increasing with fault level. As the severity of the compressor fault level was increased, the error of estimated mass flow rate increased. For this fault, the other independent virtual sensors for refrigerant flow that can be used for fault detection and diagnosis.

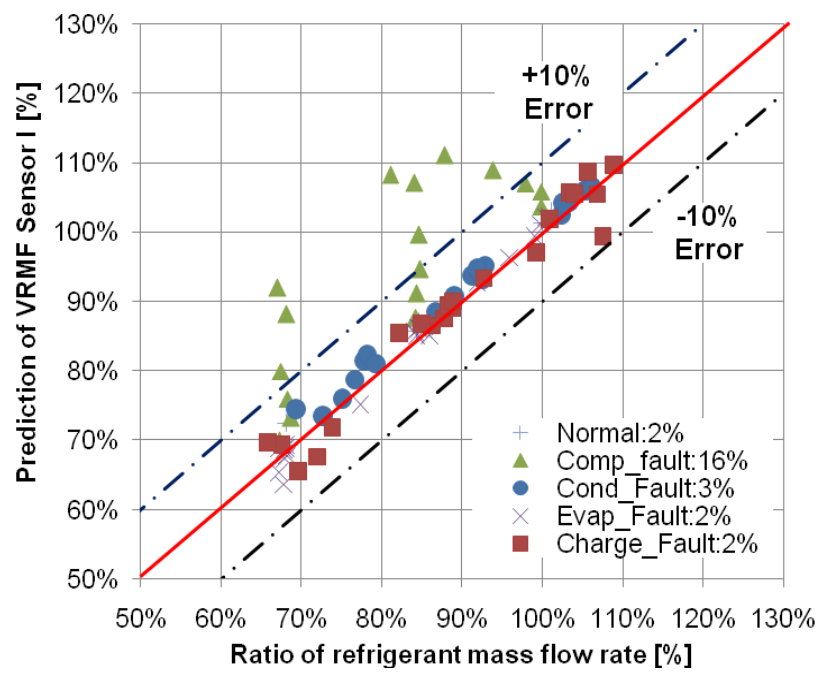

Figure 3. Performance of VRMF sensor based on variable speed compressor map for system I under no fault and fault conditions (RMS of sensor errors shown for each fault type) 


\subsection{Development of VRMF sensor II}

In order to diagnose compressor flow problems, it is necessary to have an alternative VRMF sensor. One alternative approach is to use an energy balance on the compressor to estimate flow rate as shown in equation 6. Li and Braun (2007) demonstrated that this method provides accurate flow predictions when using a virtual compressor sensor for power consumption, even in the presence of a low compressor flow or other faults. Compared to the map-based method, the energy balance model of equation 6 is much simpler and can be used for both fixed speed and variable speed compressors. ,

$$
\dot{m}_{\text {energy }}=\frac{\dot{W} \cdot\left(1-\alpha_{\text {loss }}\right)}{h_{d i s}\left(T_{d i s}, P_{d i s}\right)-h_{\text {suc }}\left(T_{\text {suc }}, P_{\text {suc }}\right)}
$$

where $\alpha_{\text {loss }}$ is compressor heat loss ratio, $\dot{W}$ is compressor power consumption, and $h_{d i s}\left(T_{d i s}, P_{d i s}\right)$ and $h_{\text {suc }}\left(T_{\text {suc }}, P_{\text {suc }}\right)$ are the discharge line and suction line refrigerant enthalpy. The compressor power consumption, discharge pressure $\left(P_{d i s}\right)$ and suction pressure $\left(P_{\text {suc }}\right)$ can be estimated using other virtual sensors (Kim and Braun, 2012).

$\alpha_{\text {loss }}$ is generally very small (under $5 \%$ ) for equipment having a fixed speed compressor operating normally. However, it can be more significant at low compressor speeds for variable speed equipment or with faults for fixed speed equipment. For example, decreasing the compressor frequency from $60 \mathrm{~Hz}$ to $30 \mathrm{~Hz}$ almost doubles the heat loss as a fraction of the power input. To provide more accurate mass flow rates predictions under various operating conditions, Li and Braun (2007) developed an empirical correlation model for equipment with fixed speed compressors in terms of compressor discharge and suction measurements, shown in equation 7. The model can be trained using regression applied to existing test data. To extend the model for equipment with variable-speed compressors, a modified empirical model was developed in this research, shown in equation 8.

$$
\begin{gathered}
\alpha_{\text {loss }, \text { pred }}=c_{0}+c_{1} P_{d i s}+c_{2} P_{\text {suc }}+c_{3} T_{d i s}+c_{4} T_{\text {suc }} \\
\alpha_{\text {loss }, \text { pred }}=c_{0}+c_{1} P_{d i s}+c_{2} P_{\text {suc }}+c_{3} T_{d i s}+c_{4} T_{s u c}+c_{5} f
\end{gathered}
$$

where the c's are empirical coefficients, $P_{s u c}$ is suction pressure, $P_{d i s}$ is discharge pressure, $T_{a m b}$ is compressor ambient temperature, $T_{s u c}$ is suction temperature, and $f$ is speed of the compressor motor.

\subsection{Performance of VRMF sensor II}

Figure 4 shows the performance of VRMF sensor II for system III with a fixed speed compressor. The mass flow rate prediction was determined using heat loss estimates and predictions of other virtual sensors. The heat loss model was determined using data for normal operation where the heat loss was determined from an energy balance on the compressor with the flow measured. The power consumption was determined using a map in terms of suction pressure and temperature and discharge pressure. The RMS error for the VRMF sensor was less than 3\% for all of the data, including both normal and faulty conditions. The larger errors for the evaporator fouling occurred when the superheat at the compressor inlet was below $0.83{ }^{\circ} \mathrm{C}$. The incorrect compressor suction enthalpy due to a two-phase refrigerant inlet 

compressor faults compared to the VRMF sensor I.

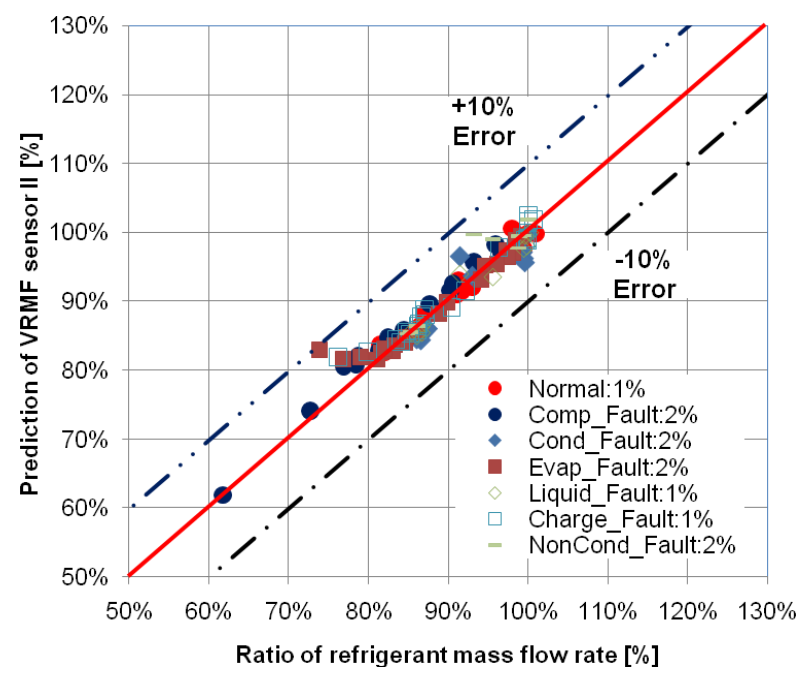

Figure 4. Performance of VRMF sensor II based on energy balance for system III under no fault and fault conditions (RMS of errors shown for each fault type)

Figure 5 shows the performance of VRMF sensor II for system I with a variable speed compressor. The mass flow rate estimates were compared to measurements for a range of different faults at different fault levels. The RMS error for the VRMF sensor II is less than 5\%. The VRMF works well regardless of the fault conditions. The largest error is at $92 \%$ mass flow rate was slightly over $10 \%$. This point is associated with low outdoor water flow rate of approximately $25 \%$ of the rated value. The cases where the VRMF sensor II had more difficulty were when the system operated with almost zero subcooling at over $75 \%$ reduction of water flow rate.

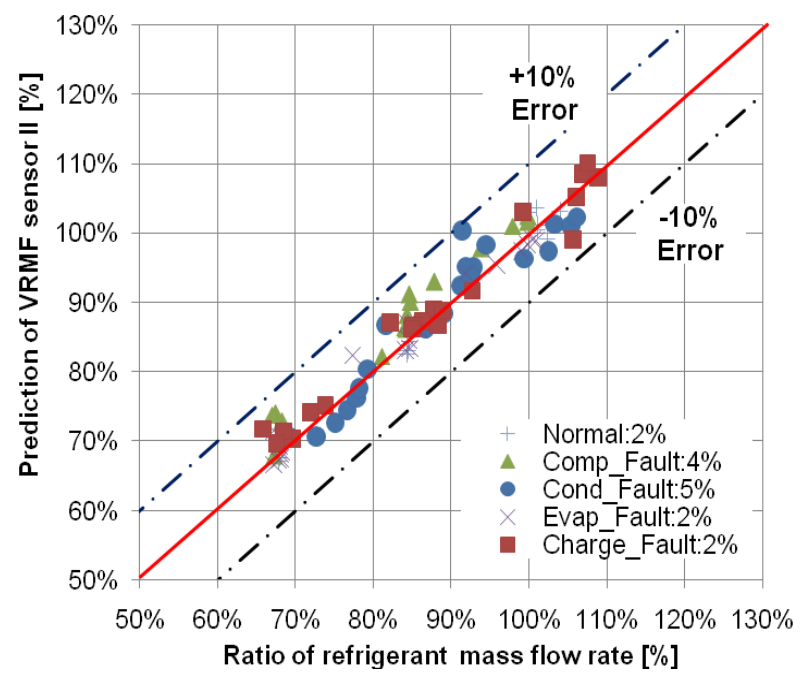

Figure 5. Performance of VRMF sensor II based on energy balance for system I under no fault and fault conditions (RMS of errors shown for each fault type) 
Expansion devices are used to drop the pressure of the refrigerant and to regulate the refrigerant mass flow rate in response to a variable load. There are three types of expansion devices typically used in air conditioners: FXO, TXV, and EEV. Even though an FXO has advantages of simplicity and low cost, it is not appropriate for a system that requires precise flow control for a wide range of flow rate requirements. TXV and EEV devices are adjustable throat-area expansion valves. The TXV adopts a mechanical control method to obtain relatively constant superheat at the evaporator outlet. The EEV provides a more precise control of superheat and fast flow control for a wide range of mass flow rates because it uses electronic actuation and sensor information along with a digital feedback controller. Most of the previous literature on modeling of expansion devices has focused on constant-area expansion devices, such as FXO. Models for predicting the mass flow characteristics of TXVs and EEVs are limited. Li and Braun (2008) developed generalized expressions for TXV mass flow as a function of superheat and valve. Shanwei et al. (2005) and Park et al. (2007) developed empirical correlations for mass flow rate through an EEV by performing dimensionless analysis based on a power law form. However, these existing models require either detailed geometric parameters or many measurements to represent performance. This paper presents VRMF sensors for TXV and EEV devices based on a semi-empirical model that can be trained using a relatively small amount of data and then can estimate refrigerant mass flow rate as part of an automated diagnostic system.

\subsection{Development of VRMF sensor III for TXV}

The valve opening for a TXV is determined by a force balance on a diaphragm, as depicted in Figure 6. The bulb and suction-line pressure act on opposite sides of the diaphragm and coupled with the spring force, control the effective orifice area. The evaporator inlet and condenser pressure influence the flow rate through the orifice for a given opening. The bulb typically contains a two-phase mixture of the same refrigerant that is employed within the system. Therefore, when a positive superheat exists at the evaporator outlet then there is a positive difference between the bulb and evaporator outlet pressures acting on the diaphragm. The spring is used to ensure a positive superheat at the evaporator exit since the bulb pressure must be greater than the evaporator exit pressure in order to overcome the force of the spring.

As depicted in Figure 6, a conical pin moves up and down to change the open area for refrigerant flow in response to the valve control. For simplicity in deriving an empirical modeling form, the mass flow rate through the TXV is assumed to be a linear function of the area at the valve opening as given in equation 9 ,

$$
\dot{m}_{T X V}=\left(\frac{A_{\text {orifice }}-A_{\text {pin }}}{A_{\text {orifice }}}\right) \cdot \dot{m}_{\max }=\frac{\pi}{4} \cdot\left(\frac{D_{\text {orifice }}^{2}-D_{\text {pin }}^{2}}{D_{\text {orifice }}^{2}}\right) \cdot \dot{m}_{\max }
$$

where $A_{\text {orifice }}$ is the area at the full opening, $A_{\text {pin }}$ is closed area associated with the pin, $D_{\text {orifice }}$ is the orifice diameter, $D_{p i n}$ is the diameter of the conical pin at the plane of the opening, and $\dot{m}_{\max }$ is the refrigerant mass flow rate associated with a full open condition.

The effective orifice area is controlled by adjusting the deflection of the spring. Since the diameter of the conical pin at the plane of the opening $\left(D_{\text {pin }}\right)$ is a linear function of deflection of spring, $D_{\text {pin }}$ can be 
expressed in terms of the position of the pin using the nomenclature provided in Figure 6 according to equation 10 ,

$$
D_{\text {pin }}=D_{\text {orifice }}\left(\frac{\max s p}{\max }\right)=D_{\text {orifice }}\left(\begin{array}{ll}
1 & \frac{s p}{\max }
\end{array}\right)
$$

where $\delta_{s p}$ is the position of the pin relative to the closed position (also the spring deflection) and $\delta_{\max }$ is the position for a fully open valve.

The $\dot{m}_{\text {max }}$ for a given valve is a function of the pressure drop across the valve and the size of the orifice. Therefore, the $\dot{m}_{\max }$ for a given orifice is calculated using the empirical correlation given in equations 11 and 12, as developed by Lenger et al. (1998),

$$
\begin{gathered}
\dot{m}_{\max }=C_{0} \cdot A_{\text {orifice }} \cdot \sqrt{\left(2 \cdot \rho_{f}\left[P_{c}-P_{e} \cdot K\right]\right)}=C_{1} \cdot \sqrt{\left(2 \cdot \rho_{f}\left[P_{c}-P_{e} \cdot K\right]\right)} \\
K=C_{2} \cdot\left(\frac{S C+2}{T_{C r i}}\right)^{C_{3}}+C_{4}\left(\frac{P_{c r i}-P_{e}}{P_{c r i}}\right)+C_{5}
\end{gathered}
$$

where the C's are empirical coefficients, $P_{c}$ is valve inlet (condensing) pressure, $P_{e}$ is evaporating (valve outlet) pressure, $\rho_{f}$ is the density of the refrigerant at the valve inlet, SC is the subcooling of the refrigerant at the valve inlet, $T_{c r i}$ and $P_{c r i}$ are the critical temperature and pressure.

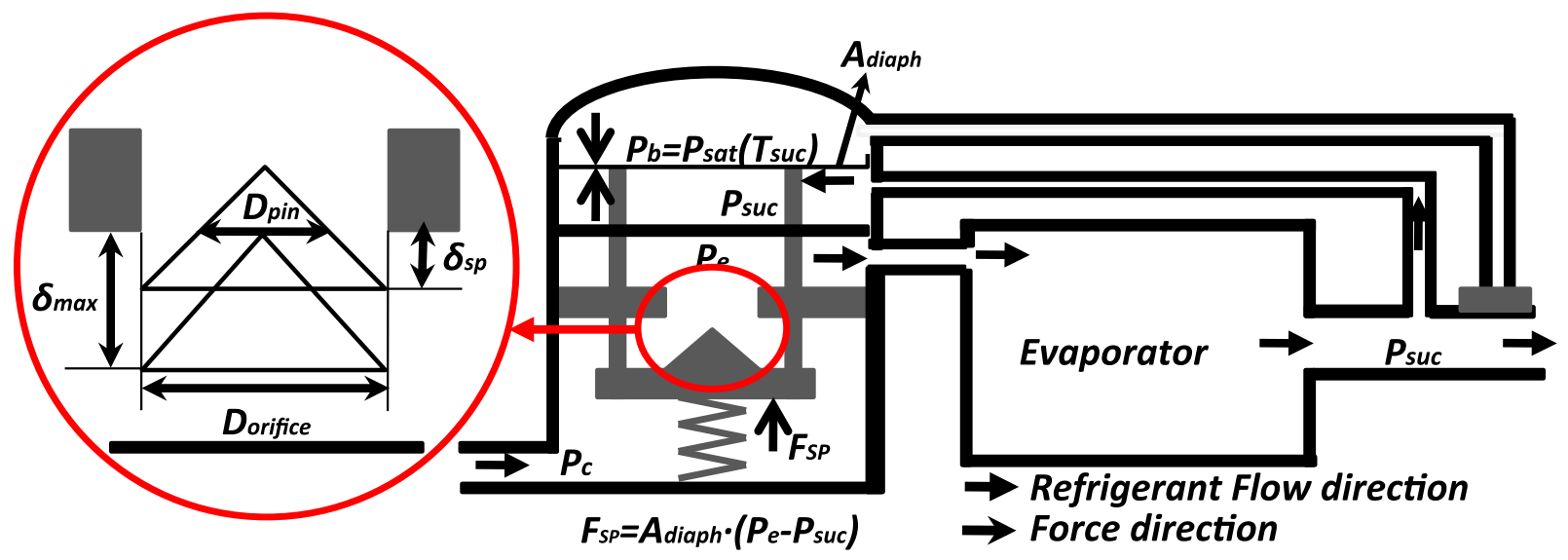

Figure 6. Diagram of TXV

The $\delta_{s p}$, needs to be determined in order to find the effective orifice area. The $\delta_{s p}$ can be found using equation 13 ,

$$
\delta_{s p}=\frac{F_{s p}-F_{s p, c l}}{k_{s p}}
$$

where $F_{s p}$ is the spring force, $F_{s p, c l}$ is the spring force when the valve is closed and $k_{s p}$ is the spring constant. Both $F_{s p, c l}$ and $k_{s p}$ are fixed for a given expansion valve. $F_{s p}$ is calculated from a quasi-static force balance on the diaphragm, as shown in equation 14 ,

$$
F_{s p}=A_{\text {diaph }} \cdot\left(P_{b}-P_{\text {suc }}\right)=A_{\text {diaph }} \cdot\left(P_{\text {sat }}\left(T_{\text {suc }}\right)-P_{\text {suc }}\right)
$$


where $P_{s u c}$ is the suction line pressure, $P_{b}$ is the bulb pressure, $P_{s a t}\left(T_{s u c}\right)$ is the saturation pressure corresponding to the temperature of the suction line and $A_{\text {diaph }}$ is the area of diaphragm. Because the bulb contains a two-phase liquid-vapor mixture, $P_{b}$ is estimated as $P_{\text {sat }}\left(T_{\text {suc }}\right)$.

Since $F_{s p}$ is a linear function of the deflection, $\delta_{s p}$ can be expressed using empirical coefficients $a$ 's, as shown in equation 15 ,

$$
\delta_{s p}=\frac{A_{\text {diaph }} \cdot\left(P_{s a t}\left(T_{s u c}\right)-P_{s u c}\right)-F_{s p, c l}}{k_{s p}}=a_{1} \cdot\left(P_{s a t}\left(T_{s u c}\right)-P_{s u c}\right)+a_{2}
$$

where $F_{s p, c l}$ is the closed spring force and $k_{s p}$ is the spring constant. $F_{s p, c l}$ and $k_{s p}$ are constants based on the valve design and initial setting.

If $\delta_{s p}$ is zero, no refrigerant flows through the orifice, and if $\delta_{s p}$ is at some maximum value, the pin will not obstruct the flow and the valve will operate at the maximum flow rate. The effective orifice area is calculated by subtracting $A_{\text {pin }}$ from the $A_{\text {orific }}$. The VRMF sensor for a TXV is developed by substituting equation 10 into equation 9, then substituting $\delta_{s p}$ from equation 15, and expressing the result in terms of new empirical coefficients that are determined through regression.

$$
\dot{m}_{T X V}=\left(1-\left(1-\frac{\delta_{s p}}{\delta_{\max }}\right)^{2}\right) \cdot \dot{m}_{\max }=\left(a_{3} \cdot\left(P_{s a t}\left(T_{s u c}\right)-P_{s u c}\right)^{2}+a_{4} \cdot\left(P_{s a t}\left(T_{s u c}\right)-P_{s u c}\right)+a_{5}\right) \cdot \dot{m}_{\max }
$$

\subsection{Performance of VRMF sensor III for TXV}

The empirical coefficients $C_{1}, C_{2}, C_{3}, C_{4}$ and $C_{5}$ within orifice equations 11 and 12 were estimated by minimizing mass flow rate prediction errors using fully open TXV test data and non-linear regression. The data for a fully-open TXV were identified by only considering data with compressor inlet superheat significantly higher than the rated superheat. These conditions occurred for refrigerant undercharge and liquid line restriction faults. The empirical coefficients $a_{3}, a_{4}$, and $a_{5}$ within the TXV model equation 16 were estimated based on the available normal test data with superheat under control using linear regression. The data includes variations in ambient temperature, and indoor dry bulb temperature with positive subcooling entering the valve. Since equation 12 uses subcooling as an input, data with small subcooling were not used for training and testing. The parameter estimation methods minimized the errors between predicted and known mass flow rates. The resulting model with empirical coefficients determined from normal data was applied to predict refrigerant mass flow rate for all of the available data including various fault conditions.

Figure 7 shows refrigerant mass flow rate estimated from the VRMF sensor III for TXV applied to system III with six different kinds of faults individually implemented. The overall RMS errors were about $1 \%$ for no fault conditions and $3 \%$ of actual mass flow rate for all fault conditions. The performance of the VRMF sensor is very good over a wide range of refrigerant mass flow rates and operating conditions regardless of the fault. There were some significant errors of about $10 \%$ for low refrigerant charge levels when the entering subcooling was almost zero. With zero subcooling and twophase conditions entering the TXV, the VRMF sensor III may not be reliable. 


\subsection{Development of VRMF sensor III for EEV}

EEVs were developed in the 1980s to provide tighter and more stable control of superheat with faster response. The applications of EEVs for high efficiency air conditioners and multi-evaporator heat pump systems have increased in recent years. However, mass flow models of EEVs for fault detection and diagnosis are very limited. In this study, the VRMF sensor based on an empirical correlation can predict refrigerant mass flow rates through an EEV.

The empirical mass flow correlation was developed by incorporating a dimensionless coefficient in terms of EEV geometries and operating conditions into the orifice equations 10 and 11 because the only difference between the EEV and TXV model is how the area opens and closes. The empirical correlation for the VRMF sensor is given in equation 17. The variation of the orifice diameter controls the refrigerant flow area for flow control. For deriving an empirical relation, the mass flow rate is assumed to proportionally increase with flow area as shown in equation 17 ,

$$
\dot{m}_{E E V}=\frac{A_{\text {flow }}}{A_{\max }} \dot{m}_{\max }=A_{\text {flow }} \cdot C_{6} \cdot \sqrt{\left(2 \cdot \rho_{f} \cdot\left[P_{c}-P_{e} \cdot K\right]\right)}
$$

where $C_{6}$ is an empirical coefficient, $A_{\text {flow }}$ is the flow area at the valve opening (see Figure 8), $\rho_{f}$ is the density of refrigerant at the valve inlet, $P_{c}$ and $P_{e}$ are the inlet pressure and evaporator pressure, and $K$ is defined in equation 12 .

Figure 8 shows the flow passage structure and geometric representation for an EEV. A needle valve moves up and down to change the flow area, typically using a stepper motor to maintain precise control of the refrigerant superheat at the evaporator exit. At a certain pin tip position $h$, the refrigerant flow area $A_{\text {flow }}$ can be calculated by subtracting the obstructing area of the needle from the area of the valve orifice as developed by $\mathrm{Li}$ and Braun (2008) and given in equation 18 .

$$
A_{\text {flow }}=\frac{\pi}{4} \cdot\left(D_{\text {orifice }}^{2}-D_{\text {pin }}^{2}\right)
$$


where $D_{\text {pin }}$ is the current needle diameter that is within the plane of the flow orifice and $D_{\text {orifice }}$ is the orifice diameter.

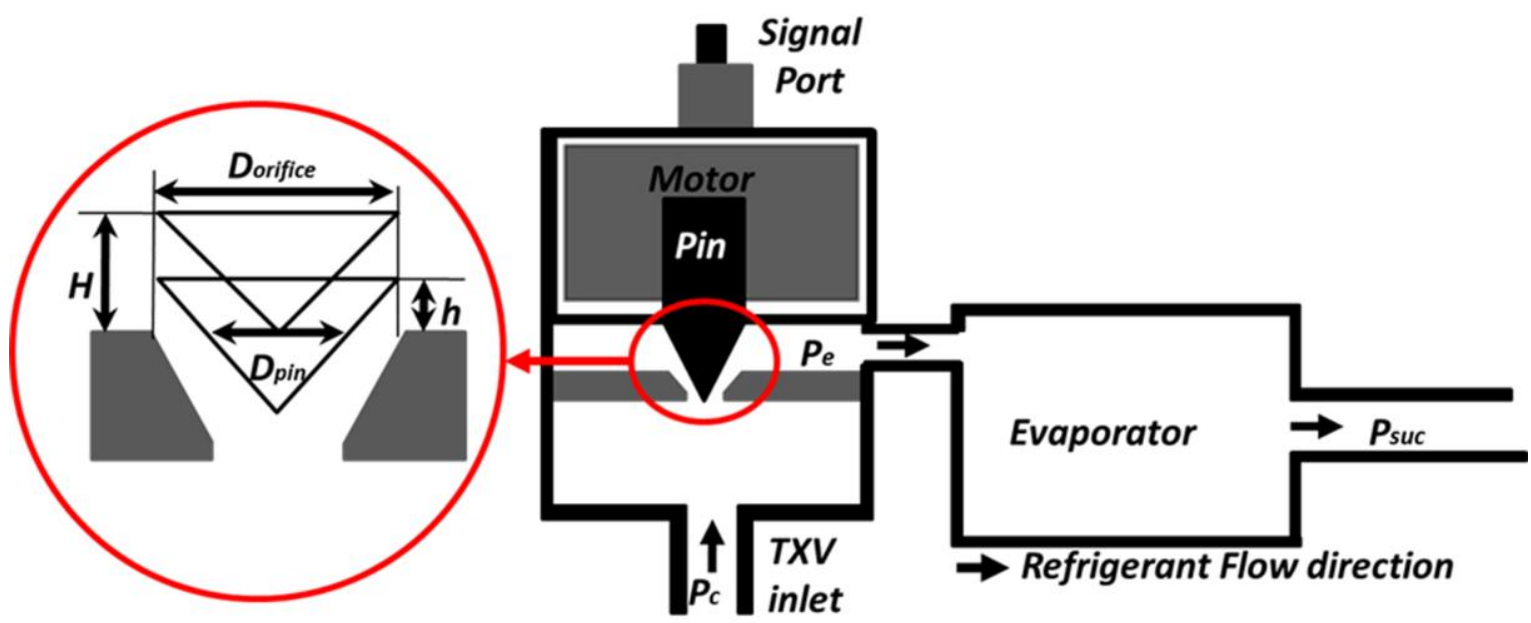

Figure 8. Flow passage structure and geometric models for EEV

Similar to the TXV, the current needle diameter can be expressed in terms of the orifice diameter and needle position as shown in equation 19 .

$$
D_{\text {pin }}=D_{\text {orifice }} \cdot\left(1-\frac{h}{H}\right)
$$

Equations 18 and 19 can be combined to express the refrigerant flow area for any needle position, $A_{\text {flow }}$, as

$$
A_{\text {flow }}=\frac{\pi}{4} \cdot\left(D_{\text {orifice }}^{2}-D_{\text {orifice }}^{2} \cdot\left(1-\frac{2 \cdot h}{H}+\left(\frac{h}{H}\right)^{2}\right)\right)=\frac{\pi}{4} \cdot D_{\text {orifice }}^{2} \cdot \frac{h}{H} \cdot\left(2-\frac{h}{H}\right)
$$

The refrigerant mass flow rate through the EEV can be obtained by substituting the refrigerant flow area, equation 20, into the general model equation 17.

$$
\dot{m}_{E E V}=C_{6} \cdot\left(\frac{\pi \cdot D_{\text {orifice }}^{2}}{4}\right) \cdot\left(\frac{h}{H}\right) \cdot\left(2-\frac{h}{H}\right) \sqrt{\left(2 \cdot \rho_{f}\left[P_{c}-P_{e} \cdot K\right]\right)}
$$

The flow area of the EEV varies with the up-and-down movement of the needle valve that is driven by a step motor. The needle position (h) is linearly proportional to the motor step of EEV, as given in equation 22 where EEVSTEP represents the number of steps relative to the closed position for the valve.

$$
h=\frac{E E V S T E P_{\text {current }}}{E E V S T E P_{\max }} \cdot H
$$




\subsection{Performance of the VRMF sensor III for EEV}

The empirical coefficients within orifice equation 11 were determined using non-linear regression applied to fully open EEV data for system I and II. Fully open EEV data were collected from the conditions where the motor step was at a maximum. Equation 11 uses subcooling as in input, and thus data with small subcooling were not used for training and testing. Once the empirical coefficients of orifice equation were obtained, the EEV equation 23 was fit to normal operating (i.e., no-fault) data using linear regression. The best-fit equation was then used to predict the refrigerant mass flow rate through the EEV for all available test data including various fault conditions.

Figure 9 shows performance of the VRMF sensor III for the EEV applied to system I. The model provides results that are generally within $6 \%$ over a wide range of mass flow rates and operating conditions. Larger errors for low refrigerant charge and condenser fouling occurred when the subcooling at the condenser outlet was below 1.1 C, but the sensor outputs are still reasonable for this fault. Overall, the VRMF sensor provides accurate estimates for both no fault and faulty conditions.

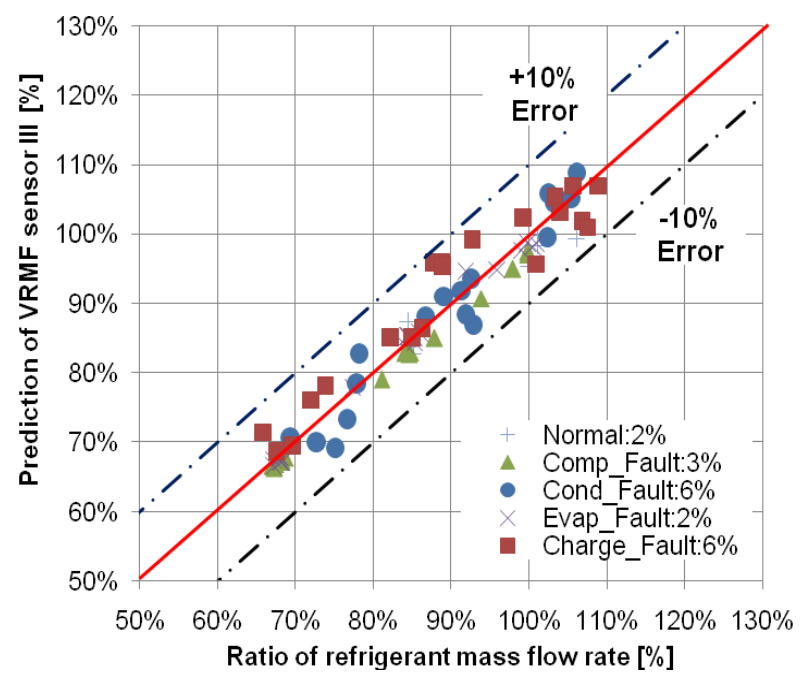

Figure 9 Performance of VRMF sensor III based on EEV for system I under no fault and fault conditions (RMS of sensor errors shown for each fault type)

Figures 10 and 11 show performance of the VRMF sensor III for EEV applied to system II with R-410A and R-404A as refrigerants. Results are presented for two different EEVs that were tested in this system. Overall, the RMS errors of the VRMF sensor III were $6 \%$ and 5\% for R-410A and R-404A, respectively. Some of the larger errors may be associated with two-phase refrigerant conditions at the EEV inlet with near-zero subcooling. 


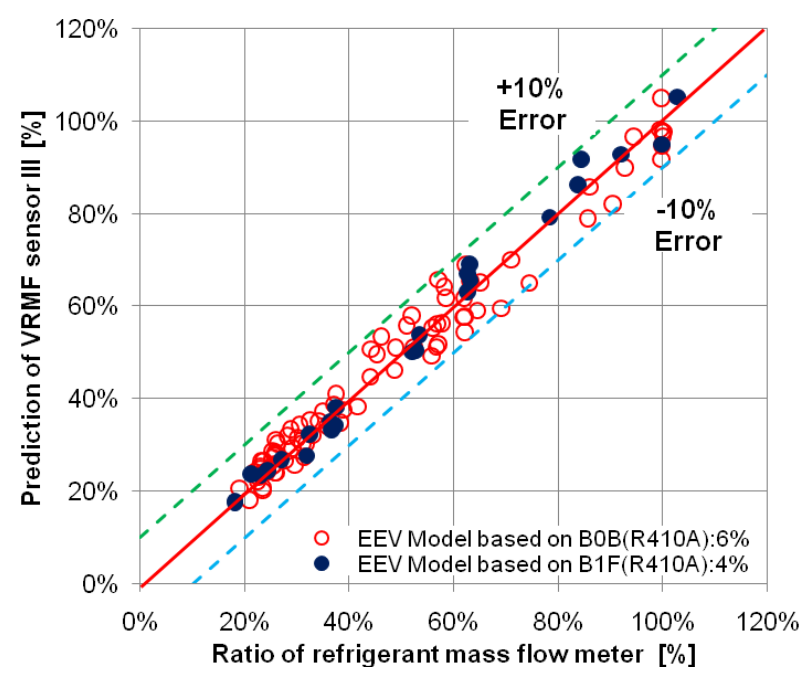

Figure 10. Performance of VRMF sensor III based on EEV with R-410A as refrigerant for system II

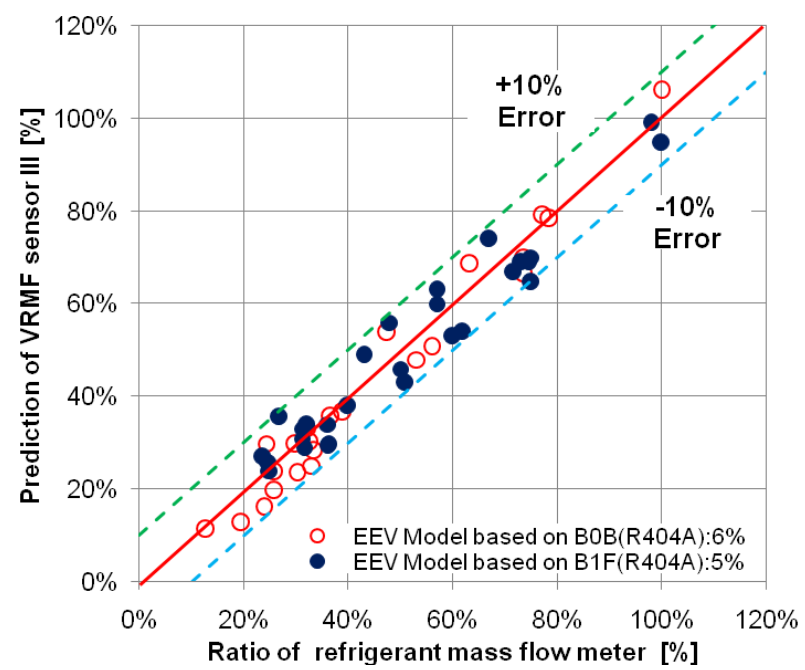

Figure 11. Performance of VRMF sensor III based on EEV with R-404A as refrigerant for system II

\section{Application of VRMF sensors}

\subsection{Comparison of VRMF sensors}

Outputs from the three VRMF sensors can be compared in order to detect a fault and localize faults within a system, including low compressor or unexpected expansion device flow. This section demonstrates the use of the VRMF sensors for isolating a fault condition where the compressor is not providing expected flow.

Figure 12 shows comparisons of the three VRMF sensors with mass flow measurements for system III operating at fixed speed with a low compressor flow (e.g., compressor discharge or suction valve leakage due to valve wear and tear) fault that was artificially introduced in the laboratory by the opening of a hot gas bypass valve. With this fault, the refrigerant mass flow rate is reduced compared to normal operation. As a result, the compressor map over-predicts refrigerant mass flow rate whereas the 
other VRMF sensors provide accurate flow estimates. The RMS errors for the compressor energy balance model and TXV models were about $2 \%$, whereas the RMS error for the fixed speed compressor model was $19 \%$. Thus, a compressor flow fault could be isolated through comparison of the VRMF sensors for this case.

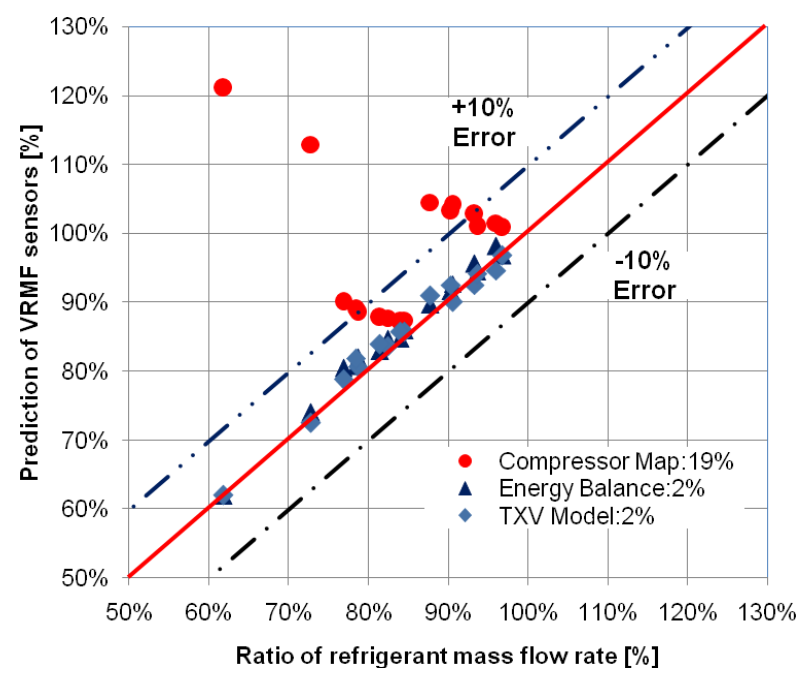

Figure 12. Comparison of VRMF sensor outputs for system III with compressor flow fault

Figure 13 shows similar results for system I having a variable speed compressor and EEV. The RMS errors for the VRMF sensors were about $5 \%$ based on a compressor energy balance and $3 \%$ based on the EEV model, but were approximately $16 \%$ for the variable speed compressor map.

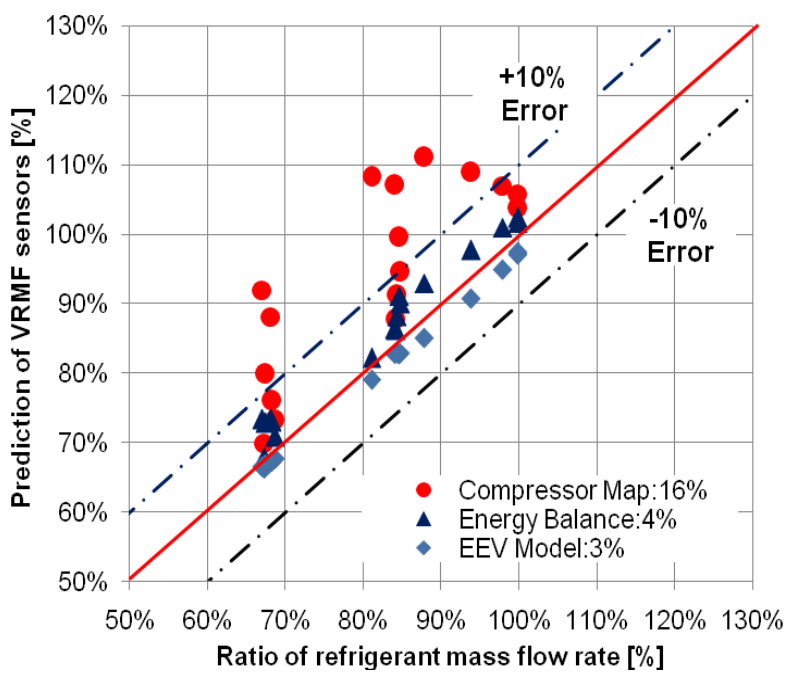

Figure 13. Comparison of VRMF sensor outputs for system I with compressor flow fault

Figure 14 and 15 show results for system II with B1F and B0B as expansion devices and the two different refrigerant types, R-410A and R-404a. The data did not include information that could be used to evaluate the energy balance method. The tests covered a wide range of compressor fault levels from 10 to $100 \%$. For either set of test data, a compressor fault could be readily identified by comparing predictions of the compressor map with those from the EEV model. 


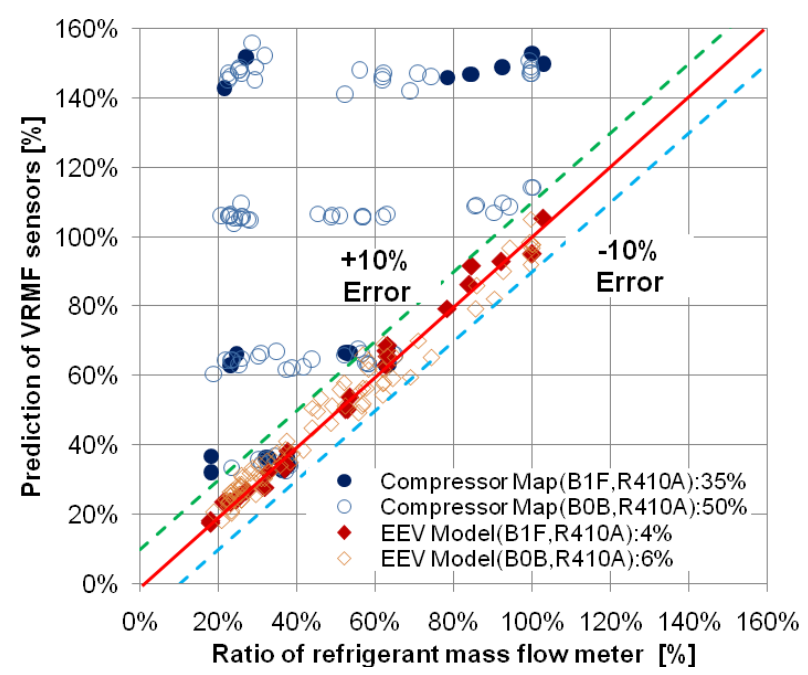

Figure 14. Comparison of VRMF sensor outputs for system II (R410A) with compressor flow fault

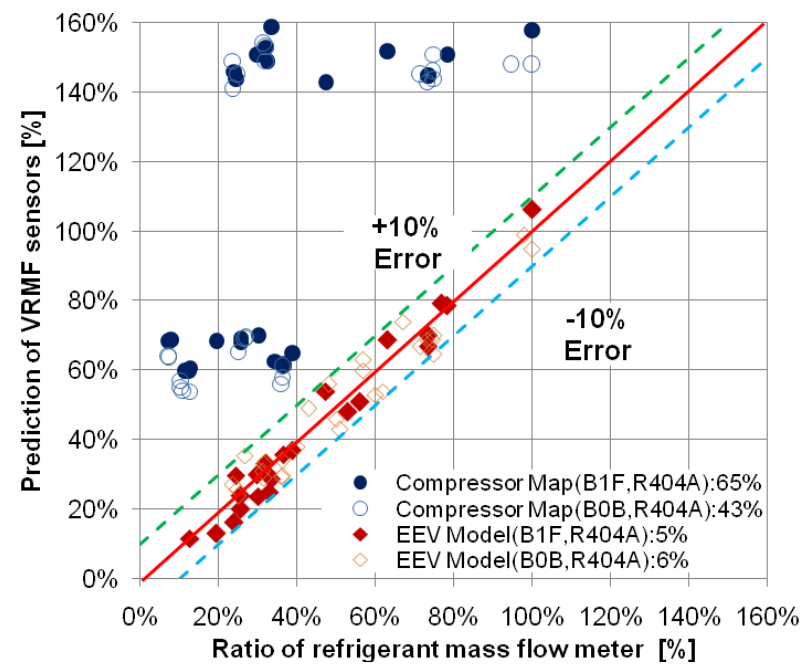

Figure 15. Comparison of VRMF sensor outputs for system II (R404A) with compressor flow fault

Faults can be detected by comparing the current estimations from the VRMF sensors and expected values for a normal condition. VRMF sensors use a compressor map and a TXV model as current predictions and energy balance as a normal expected prediction. The classifier is applied to each combination of residuals between two predictions to identify the existence of low compressor flow caused by a leaky compressor valve and/or a faulty expansion device.

\subsection{VRMF sensors for fault detection}

There are several possible statistical classifier designs for fault detection. A Bayesian classifier is optimal with respect to minimizing the classification error associated with current and normal distributions of residuals (Fukunaga 1990). The classification error is the overlap area between probability distributions of residuals for current and normal operation, shown in Figure 16. Under normal operation, there is a distribution of residuals caused by the measurement noise signals and modeling errors. 
In this study, the fault detection thresholds were determined based on analysis of normal data. If thresholds were set too close to normal conditions, fault detection would be too sensitive, leading to false alarms. If thresholds were set too far from normal conditions, fault detection might miss faults that significantly reduce system performance. Therefore, it is important to define reasonable thresholds for effective fault detection.

\subsubsection{Statistical Bayesian Classifier}

Based on the Bayesian decision theorem,

$$
P\left(\omega_{i} \mid x\right)=\frac{P\left(x \mid \omega_{i}\right) P\left(\omega_{i}\right)}{P(x)}
$$

where $P\left(\omega_{i} \mid x\right)$ is the conditional probability of $\omega_{i}$ having accounted for evidence $x . P\left(\omega_{i}\right)$ is prior probability, and $P\left(x \mid \omega_{i}\right)$ is the class conditional probability density function. Since $P(x)$ is positive and common to both sides of the inequality, the Bayesian decision rule of equation 24 can be expressed as

$$
\begin{gathered}
\omega_{1}(\text { Normal }): P\left(x \mid \omega_{1}\right) p\left(\omega_{1}\right) \geq P\left(x \mid \omega_{2}\right) P\left(\omega_{2}\right), \quad \omega_{2}(\text { fault }): P\left(x \mid \omega_{1}\right) P\left(\omega_{1}\right) \leq P\left(x \mid \omega_{2}\right) P\left(\omega_{2}\right) \\
l(x)=\frac{P\left(x \mid \omega_{1}\right)}{P\left(x \mid \omega_{2}\right)}=\frac{P\left(\omega_{2}\right)}{P\left(\omega_{1}\right)} \\
h(x)=-\log l(x)=-\log \left(\frac{P\left(x \mid \omega_{1}\right)}{P\left(x \mid \omega_{2}\right)}\right)=-\log P\left(x \mid \omega_{1}\right)+\log P\left(x \mid \omega_{2}\right)=\log P\left(\omega_{2}\right)-\log P\left(\omega_{1}\right)
\end{gathered}
$$

where $1(x)$ is the likelihood ratio, which is the basic quantity in hypothesis testing and $h(x)$ is the discriminant function.

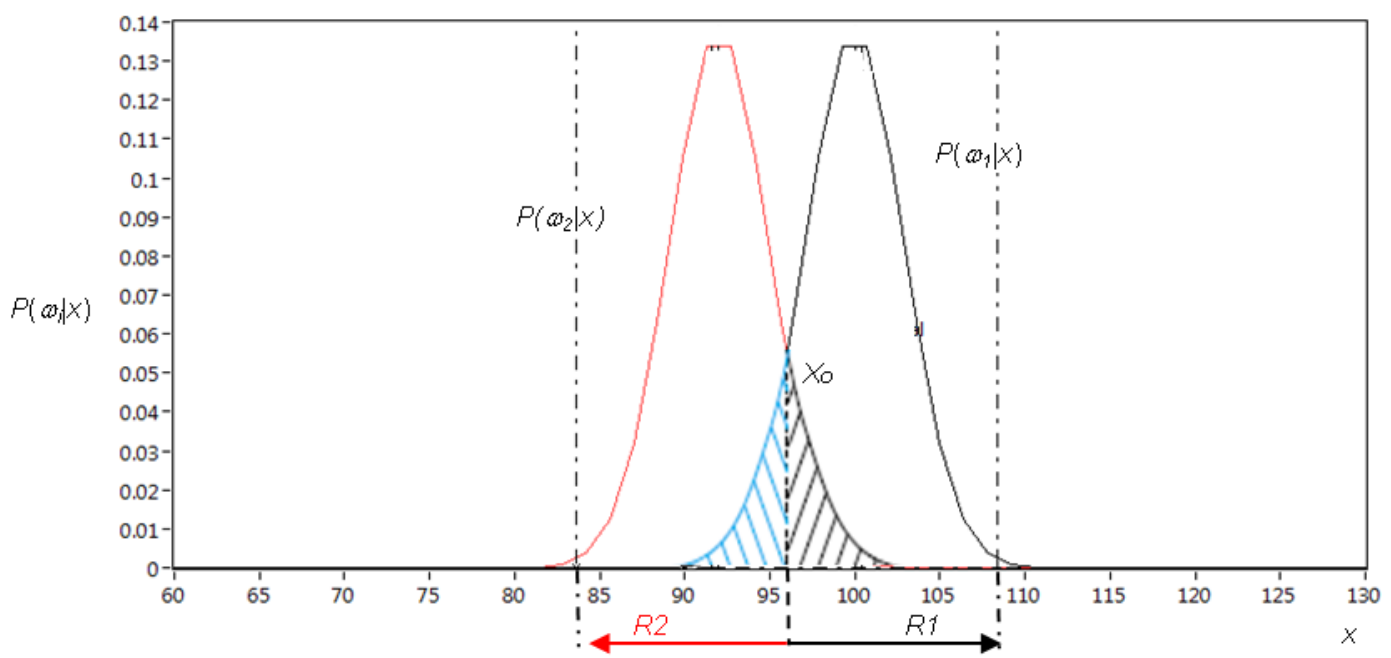

Figure 16. Bayesian decision rule for minimum error $\left(\omega_{1}\right.$ : No fault \& $\omega_{2}$ : fault condition)

Figure 16 shows two conditional probabilities $P\left(x \mid \omega_{i}\right), i=1,2$, as functions of $\mathrm{x}$ in each of the classes. The dashed line at $x_{0}$ is a threshold partitioned into two regions, $R_{1}$ and $R_{2}$. According to the Bayesian decision rule, for all $x$ values in $R_{1}$ the classifier decides $\omega_{1}$ and for all $x$ values in $R_{2}$ it decides $\omega_{2}$. However, there is overlapping probability, which is equal to the total shaded area under the curves 
belonging in $R_{1}$ and $R_{2}$, shown in Figure 16. The shaded area is the Bayesian classification error probability $(\varepsilon)$, which is given by

$$
\varepsilon=\int_{x_{o}}^{\infty} p\left(x \mid \omega_{1}\right) p\left(\omega_{1}\right) d x+\int_{-\infty}^{x_{o}} p\left(x \mid \omega_{2}\right) p\left(\omega_{2}\right) d x=p\left(\omega_{1}\right) \varepsilon_{1}+p\left(\omega_{2}\right) \varepsilon_{2}
$$

The classification error probability for abnormal operation should be lower than the error for normal operation based on statistical analysis. One of the most common probability density functions in practice is the normal probability density function. When $P\left(x \mid \omega_{i}\right)$ is the normal distribution with mean $\mu_{i}$ and covariance $\Sigma_{i}$, shown in equation 29 , equation 30 can be derived from equations 27 and 29,

$$
\begin{gathered}
p\left(x \mid \omega_{1}\right) \sim N\left(\mu_{1}, \Sigma_{1}\right), \quad p\left(x \mid \omega_{2}\right) \sim N\left(\mu_{2}, \Sigma_{2}\right) \\
g_{i}(x)=\log p\left(x \mid \omega_{i}\right)=\frac{-\left(x-\mu_{i}\right)^{t} \sum_{i}^{-1}\left(x-\mu_{i}\right)}{2}+\log \left(\frac{1}{\sqrt{\left(2 \pi \Sigma_{i}\right)}}\right)
\end{gathered}
$$

where $x$ is a vector of current residuals, $\mu_{1}$ is the mean describing the distribution of normal residuals and $\Sigma_{1}$ is the covariance describing the uncertainty of residuals without faults. $\mu_{2}$ is the mean describing the distribution of current residuals and $\Sigma_{2}$ is the covariance describing the uncertainty of current residuals.

If covariance matrices are assumed to be the same, $\Sigma=\Sigma_{1}=\Sigma_{2}$, then

$$
\begin{gathered}
\frac{-\left(x-\mu_{1}\right)^{t} \Sigma_{1}^{-1}\left(x-\mu_{1}\right)}{2}+\log \left[P\left(\omega_{1}\right)\right]=\frac{-\left(x-\mu_{2}\right)^{t} \Sigma_{2}^{-1}\left(x-\mu_{2}\right)}{2}+\log \left[P\left(\omega_{2}\right)\right] \\
h(x)=\left(\mu_{2}-\mu_{1}\right)^{t} \Sigma^{-1} x+\frac{1}{2}\left(\mu_{1}^{t} \Sigma^{-1} \mu_{1}-\mu_{2}^{t} \Sigma^{-1} \mu_{2}\right)=\log \left[P\left(\omega_{1}\right) / P\left(\omega_{2}\right)\right] .
\end{gathered}
$$

Equation 32 is a linear discriminant function based on 1) the optimum coefficient $V^{t}$ and 2) the threshold for a given distribution $v_{0}$ as shown in equation 33 ,

$$
h(x)=\left(\mu_{2}-\mu_{1}\right)^{t} \Sigma^{-1} x+\frac{1}{2}\left(\mu_{1}^{t} \Sigma^{-1} \mu_{1}-\mu_{2}^{t} \Sigma^{-1} \mu_{2}\right)=V^{t} x+v_{0} .
$$

The expected value and variance of $\mathrm{h}(\mathrm{x})$ can be calculated by

$$
\begin{gathered}
\eta_{i}=E\left(h(x) \mid x \in \omega_{i}\right)=\left(\mu_{2}-\mu_{1}\right)^{t} \Sigma^{-1} E\left(x \mid \omega_{i}\right)+\frac{1}{2}\left(\mu_{1}^{t} \Sigma^{-1} \mu_{1}-\mu_{2}^{t} \Sigma^{-1} \mu_{2}\right) \\
\sigma_{i}^{2}=E\left(\left(h(x)-\eta_{1}\right)^{2} \mid x \in \omega_{i}\right)=E\left(\left(\mu_{2}-\mu_{1}\right)^{t} \Sigma^{-1}\left(x-\mu_{1}\right) \mid \omega_{i}\right)
\end{gathered}
$$

where $\eta$ is the squared Mahalanobis distance between $\mu_{1}$ and $\mu_{2}$. The Mahalanobis distance is a good measure of separation between normal and fault classes. $P\left(h(x) \mid \omega_{1}\right)$ is a normal distribution with mean $-\eta$ and covariance $2 \eta$, and $P\left(h(x) \mid \omega_{2}\right)$ is a normal distribution with mean $+\eta$ and covariance $2 \eta$.

The hatched areas in Figure 16 correspond to the error probabilities and can be expressed as

$$
\varepsilon_{1}=\int_{x_{o}=\log \left[\frac{P\left(\omega_{1}\right)}{P\left(\omega_{2}\right)}\right]}^{\infty} P\left(h(x) \mid x \in \omega_{1}\right) d h=\int_{\frac{\eta+t}{\sqrt{2 \eta}}}^{\infty} \frac{1}{\sqrt{2 \pi}} e^{-\frac{1}{2} \xi^{2}} d \xi=\frac{1}{2}-\frac{1}{2} \operatorname{erf}\left(\frac{\eta+t}{\sqrt{4 \eta}}\right)
$$




$$
\varepsilon_{2}=P\left(g_{2}(x)<g_{1}(x) \mid x \in \omega_{2}\right)=\frac{1}{2}-\frac{1}{2} \operatorname{erf}\left(\frac{\eta-t}{\sqrt{4 \eta}}\right) .
$$

\subsubsection{Fault detection and diagnosis analysis}

For fault detection and diagnosis, the Bayesian classifier is applied to the residuals of refrigerant mass flow rate obtained with the three VRMF sensors. A fault detection classifier is applied to each combination of residuals to identify the existence of a fault. If a fault is detected based on statistical evaluation of the residuals, then fault diagnosis is accomplished by identifying the specific virtual measurement that is responsible. The reference flow is determined with the compressor energy balance. If the compressor map flow is significantly higher than the reference, then compressor performance has degraded. If the predicted expansion valve flow is significantly different than the reference, then the valve is not working properly. If both compressor map and expansion valve flows are significantly different than the reference, then either both faults exist or there is compressor motor fault or other problem that is causing errors in the virtual power input to the compressor energy balance. For this example, there are two possible fault diagnoses that were considered: low compressor flow (due to a leaky compressor valve or other internal compressor fault) and a faulty expansion device. Figure 17 shows a flowchart for fault detection and diagnosis using the three VRMF sensors.

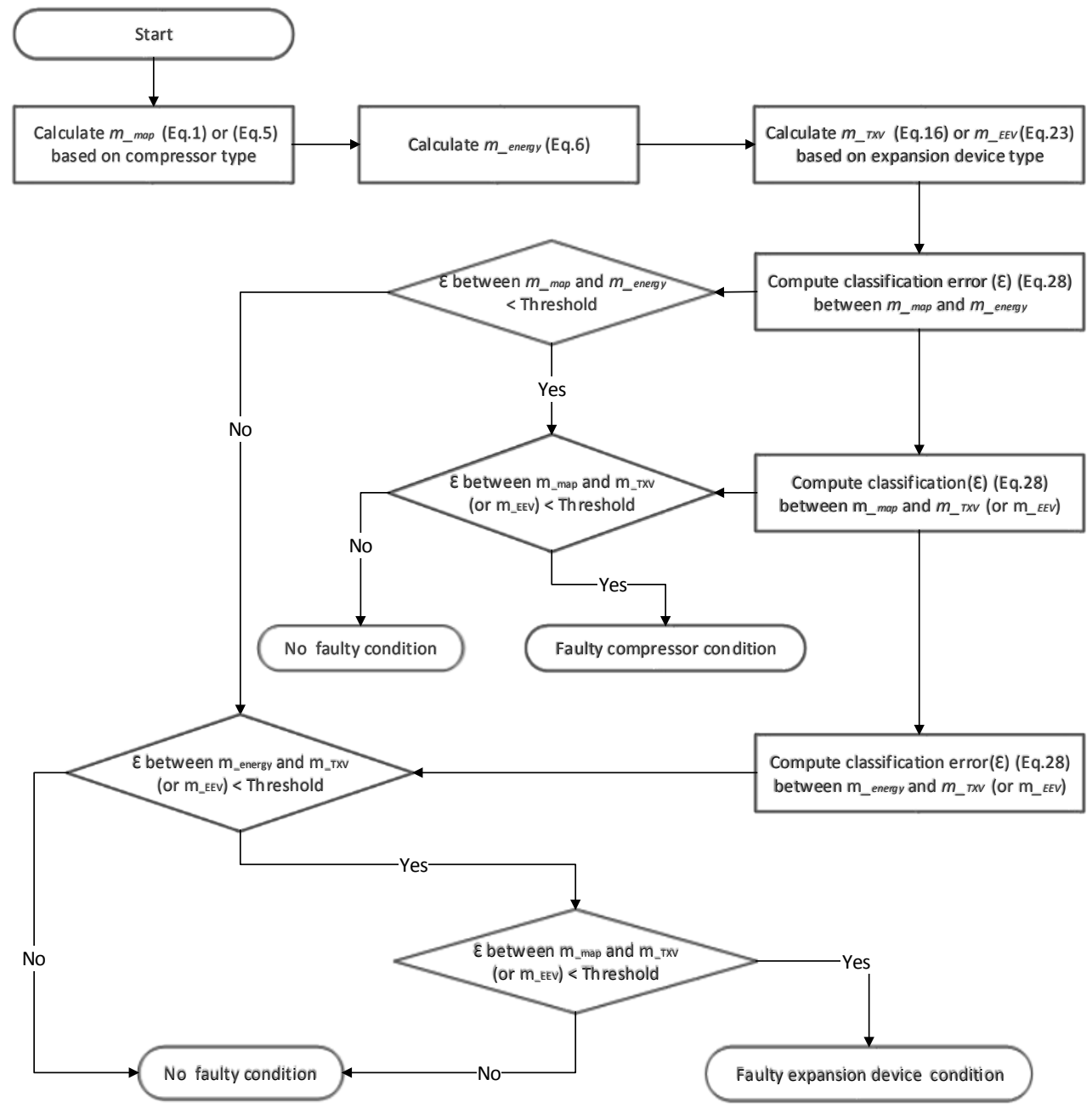

Figure 17. Flowcart for fault detection and diagnosis based on three VRM sensors 
Data for system III was used to evaluate the different fault detection classification methods and demonstrate the application of the VRMF sensors for fault diagnosis. Table 4 shows the results of the analysis of the normal data used to determine the fault detection thresholds for the Bayesian classifier error. The minimum classification error associated with normal operation based on analysis of normal data for VRMF results was found to be 7.84E-03 as shown in the table. Faults were identified if the deviation was lower than the minimum threshold value.

Table 4 Calculation of threshold for Bayesian classifier based on normal data for VRMF outputs

\begin{tabular}{|c|c|c|c|c|c|c|}
\hline \multicolumn{4}{|c|}{ Test Condition for system III } & $\begin{array}{l}\text { 1) Compressor Map / } \\
\text { 2) Energy balance }\end{array}$ & $\begin{array}{l}\text { 1) Compressor Map / } \\
\text { 3) Expansion device }\end{array}$ & $\begin{array}{l}\text { 2) Energy balance / } \\
\text { 3) Expansion device }\end{array}$ \\
\hline \multirow{2}{*}{ \# } & \multicolumn{2}{|c|}{ ID Temp. } & \multirow{2}{*}{$\begin{array}{c}\text { OD } \\
\text { Temp.[C] }\end{array}$} & \multirow{2}{*}{ Classification Error $(\varepsilon)$} & \multirow{2}{*}{ Classification Error $(\varepsilon)$} & \multirow{2}{*}{ Classification Error $(\varepsilon)$} \\
\hline & $\mathrm{DB}[\mathrm{C}]$ & $\mathrm{WB}[\mathrm{C}]$ & & & & \\
\hline 1 & 20 & 15 & \multirow{2}{*}{29} & 7.84E-03* & 1.26E-02* & 9.30E-03* \\
\hline 2 & 27 & 19 & & $2.07 \mathrm{E}-02$ & $1.49 \mathrm{E}-02$ & $3.41 \mathrm{E}-02$ \\
\hline 3 & 20 & 15 & \multirow{2}{*}{35} & $6.06 \mathrm{E}-02$ & $2.99 \mathrm{E}-02$ & $4.92 \mathrm{E}-02$ \\
\hline 4 & 27 & 19 & & $7.79 \mathrm{E}-02$ & $3.51 \mathrm{E}-02$ & $5.02 \mathrm{E}-02$ \\
\hline 5 & 20 & 15 & \multirow{2}{*}{40} & $2.91 \mathrm{E}-02$ & $1.55 \mathrm{E}-02$ & $3.13 \mathrm{E}-02$ \\
\hline 6 & 27 & 19 & & $4.68 \mathrm{E}-02$ & $1.85 \mathrm{E}-02$ & $3.13 \mathrm{E}-02$ \\
\hline
\end{tabular}

Table 5 shows outputs from the Bayesian fault detection classifier for a compressor valve leakage fault. The fault level is the percentage of the total refrigerant mass flow rate that is bypassed to the compressor suction line. The classification errors for residuals involving the compressor map were less than the threshold and indicated faults for most of the faulty cases. However, residuals for the energy balance and expansion valve sensors were greater than the thresholds with no fault indications. Based on the results, low compressor flow could be diagnosed as a fault. Although there were two points that were missed, the impact of the fault on performance (COP and capacity) was less than $10 \%$ when the fault level was within $10 \%$ of rated refrigerant mass flow rates. .

Table 5 FDD responses of VRMF sensors to compressor valve leakage based on Bayesian classifier

\begin{tabular}{|c|c|c|c|c|c|c|c|}
\hline \multirow{4}{*}{ Test } & $\begin{array}{c}\text { Fault } \\
\text { Level } \\
{[\%]}\end{array}$ & \multicolumn{2}{|c|}{$\begin{array}{c}\text { 1) Compressor Map / } \\
\text { 2) Energy balance }\end{array}$} & $\begin{array}{c}\text { 1) Compressor Map / } \\
\text { 3) Expansion device }\end{array}$ & \multicolumn{2}{|c|}{$\begin{array}{c}\text { 2) Energy Balance / } \\
\text { 3) Expansion device }\end{array}$} \\
\cline { 3 - 9 } & $\begin{array}{c}\text { Classification } \\
\text { Error }(\varepsilon)\end{array}$ & Diagnosis & $\begin{array}{c}\text { Classification } \\
\text { Error }(\varepsilon)\end{array}$ & Diagnosis & \multicolumn{2}{c|}{$\begin{array}{c}\text { Classification } \\
\text { Error }(\varepsilon)\end{array}$} & Diagnosis \\
\hline \multirow{4}{*}{3} & 2.50 & $1.31 \mathrm{E}-02$ & No Fault & $4.67 \mathrm{E}-02$ & No Fault & $3.13 \mathrm{E}-02$ & No Fault \\
\cline { 2 - 9 } & 5.00 & $2.04 \mathrm{E}-04$ & Fault & $1.02 \mathrm{E}-02$ & No Fault & $3.44 \mathrm{E}-02$ & No Fault \\
\cline { 2 - 9 } & 9.30 & $0.00 \mathrm{E}+00$ & Fault & $1.63 \mathrm{E}-05$ & Fault & $3.51 \mathrm{E}-02$ & No Fault \\
\cline { 2 - 9 } & 11.40 & $0.00 \mathrm{E}+00$ & Fault & $5.64 \mathrm{E}-08$ & Fault & $3.49 \mathrm{E}-02$ & No Fault \\
\hline \multirow{4}{*}{4} & 4.00 & $6.80 \mathrm{E}-05$ & Fault & $1.51 \mathrm{E}-04$ & Fault & $2.61 \mathrm{E}-02$ & No Fault \\
\cline { 2 - 9 } & 6.70 & $0.00 \mathrm{E}+00$ & Fault & $3.25 \mathrm{E}-08$ & Fault & $2.91 \mathrm{E}-02$ & No Fault \\
\cline { 2 - 9 } & 9.50 & $0.00 \mathrm{E}+00$ & Fault & $0.00 \mathrm{E}+00$ & Fault & $3.21 \mathrm{E}-02$ & No Fault \\
\cline { 2 - 9 } & 27.20 & $0.00 \mathrm{E}+00$ & Fault & $0.00 \mathrm{E}+00$ & Fault & $3.50 \mathrm{E}-02$ & No Fault \\
\cline { 2 - 9 } & 38.20 & $0.00 \mathrm{E}+00$ & Fault & $0.00 \mathrm{E}+00$ & Fault & $2.91 \mathrm{E}-02$ & No Fault \\
\hline
\end{tabular}

Table 6 shows outputs from the Bayesian classifier under low refrigerant charge, condenser fouling, and liquid line restriction faults. All values were higher than the threshold, and thus no refrigerant flow faults were detected. The results suggest that this method correctly decouples refrigerant flow faults from other faults in the system. 
Table 6 FDD responses of VRMF sensors to 1) low refrigerant charge, 2) condenser fouling, and 3) liquid line restriction faults based on Bayesian classifier

\begin{tabular}{|c|c|c|c|c|c|c|c|}
\hline \multirow{2}{*}{ Test } & \multirow{2}{*}{$\begin{array}{c}\text { Fault } \\
\text { Level } \\
{[\%]}\end{array}$} & \multicolumn{2}{|c|}{$\begin{array}{l}\text { 1) Compressor Map / } \\
\text { 2) Energy balance }\end{array}$} & \multicolumn{2}{|c|}{$\begin{array}{l}\text { 1) Compressor Map / } \\
\text { 3) Expansion device }\end{array}$} & \multicolumn{2}{|c|}{$\begin{array}{l}\text { 2) Energy Balance / } \\
\text { 3) Expansion device }\end{array}$} \\
\hline & & $\begin{array}{c}\text { Classification } \\
\text { Error }(\varepsilon)\end{array}$ & Diagnosis & $\begin{array}{c}\text { Classification } \\
\text { Error }(\varepsilon)\end{array}$ & Diagnosis & $\begin{array}{c}\text { Classification } \\
\text { Error }(\varepsilon)\end{array}$ & Diagnosis \\
\hline \multirow{14}{*}{5} & \multicolumn{7}{|c|}{ Refrigerant Charge fault } \\
\hline & -10.00 & $8.50 \mathrm{E}-02$ & No Fault & $3.04 \mathrm{E}-02$ & No Fault & $2.61 \mathrm{E}-02$ & No Fault \\
\hline & -20.00 & $1.48 \mathrm{E}-02$ & No Fault & $3.08 \mathrm{E}-02$ & No Fault & $1.22 \mathrm{E}-02$ & No Fault \\
\hline & -30.00 & $5.69 \mathrm{E}-03$ & No Fault & $4.42 \mathrm{E}-02$ & No Fault & $1.45 \mathrm{E}-02$ & No Fault \\
\hline & \multicolumn{7}{|c|}{ Condenser fouling fault } \\
\hline & 5.00 & $5.95 \mathrm{E}-02$ & No Fault & $3.85 \mathrm{E}-02$ & No Fault & $3.46 \mathrm{E}-02$ & No Fault \\
\hline & 10.00 & $6.17 \mathrm{E}-02$ & No Fault & $5.02 \mathrm{E}-02$ & No Fault & $3.47 \mathrm{E}-02$ & No Fault \\
\hline & 20.00 & $1.48 \mathrm{E}-02$ & No Fault & $5.08 \mathrm{E}-02$ & No Fault & $2.90 \mathrm{E}-02$ & No Fault \\
\hline & 35.00 & $4.34 \mathrm{E}-02$ & No Fault & $4.61 \mathrm{E}-02$ & No Fault & $3.00 \mathrm{E}-02$ & No Fault \\
\hline & 50.00 & $8.01 \mathrm{E}-03$ & No Fault & $5.05 \mathrm{E}-02$ & No Fault & $2.86 \mathrm{E}-02$ & No Fault \\
\hline & \multicolumn{7}{|c|}{ Liquid line restriction fault } \\
\hline & 5.30 & $5.73 \mathrm{E}-02$ & No Fault & $5.19 \mathrm{E}-02$ & No Fault & $3.30 \mathrm{E}-02$ & No Fault \\
\hline & 10.40 & $7.55 \mathrm{E}-02$ & No Fault & $4.92 \mathrm{E}-02$ & No Fault & $3.19 \mathrm{E}-02$ & No Fault \\
\hline & 20.20 & $7.44 \mathrm{E}-02$ & No Fault & $4.77 \mathrm{E}-02$ & No Fault & $3.50 \mathrm{E}-02$ & No Fault \\
\hline
\end{tabular}

\section{Conclusions}

Refrigerant mass flow rate is an important measurement for equipment performance monitoring, fault detection, and diagnostics. However, a typical refrigerant mass flow meter is expensive and installation for existing field equipment is complicated because it requires an equipment modification that can lead to refrigerant leakage. To enable low-cost implementations for on-line performance monitoring and automated diagnostics, three different VRMF sensors were developed for estimating refrigerant mass flow rate from low-cost measurements that are based on: 1) a compressor map, 2) a compressor energy balance, and 3) a semi-empirical correlation for the expansion device (TXV or EEV).

The VRMF sensors presented in this paper were validated for systems having fixed and variable speed compressors, different refrigerants, and different expansion devices (TXV/EEV) operating over a wide range of operating conditions both with and without faults. The three VRMFs worked well in estimating the refrigerant mass flow rate for the various systems under fault-free conditions with less than a 5\% RMS error. Predictions from the VRMF sensor based on a compressor map deviate from the other VRMF sensors in the presence of a compressor fault with the deviations growing with the magnitude of the fault. These differences can be used within a diagnostic system to isolate this particular fault since the accuracy of the energy balance model and expansion device models are independent of compressor flow faults.

\section{Acknowledgement}

This work was supported by the Department of Energy through the Consortium for Building Energy Innovation (formerly the Energy Efficient Buildings Hub). 
ADM Associates, 2009, Market assessment and field M\&V study for comprehensive packaged A/C systems program, Final report (SCE0286.01), July24, 2009.

Aprea, C., Mastrullo, R., and Renno, C., 2004, Fuzzy control of the compressor speed in a refrigeration plant, International Journal of Refrigeration, Vol.27(6), 639-648.

ARI, 1999, "Positive Displacement Refrigerant Compressors and Compressor Units", ANSI/ARI Standard 540-1999, Air-Conditioning \& Refrigerant Institute, Arlington, VA.Aprea C., Mastrullo R., and Renno C., 2004, Fuzzy control of the compressor speed in a refrigeration plant, International Journal of Refrigeration, Vol.27(6), 639-649.

Bach, C., Groll, E.A., and Braun, J.E., 2012, Virtual EXV mass flow sensor for applications with twophase flow inlet conditions, 14th International Refrigerant and Air conditioning Conference, West Lafayette, IN 47906.

Brodrick, J., 2000, Are fans blowing your energy budget?, Heating/Piping/Air Conditioning Engineering, 74-77.

Browne M.W. and Bansal P.K., 2002, Transient simulation of vapor compression packaged liquid chillers, International Journal of Refrigeration, Vol.25(5), 597-610.

Energy Efficiency and Renewable Energy, 2008, Energy efficiency trends in residential and commercial buildings, US Department of Energy.

Fukunaga, K., 1990, Introduction to statistical pattern recognition, Academic Press, West Lafayette, IN 47906.

Katipamula, S. and Brambley, M.R., 2005. Methods for fault detection, diagnostics, and prognostics for vapor compression equipment Systems, A Review, Part I, HVAR\&R Research, Vol.11(1), 3-25.

Kim, M. and Kim, M. S., 2005, Performance investigation of a variable-speed vapor compression system for fault detection and diagnosis, International Journal of Refrigerant, Vol. 28(4), 481-488.

Kim, M., Yoon, S. H., Payne, W. V., and Domanski, P. A., 2008, Cooling mode fault detection and diagnosis method for a residential heat pump., NIST Spec. Publ. 1087, Natl. Inst. of Stds. Techn., Gaithersburg, MD, USA.

Kim, M., Payne, W. V., Domanski, P. A., and C.J.L. Hermes, 2009, Performance of a Residential Heat Pump Operating in the Cooling Mode with Single Faults Imposed., Applied Thermal Engineering, Vol.29, 770-778

Kim, W and Braun, J.E., 2012, Virtual refrigerant mass flow and power sensors for variable-speed compressors, 14th International Refrigerant and Air conditioning Conference, West Lafayette, IN 47906.

Lenger, M. J., Jacobi A.M., and Hrnjak, P. S.,1998, "Superheat Stability of an Evaporator and Thermostatic Expansion Valve” ACRC Technical Report No. 138. 
Li, H. and Braun, J. E., 2007, Decoupling features and virtual Sensors for diagnosis of faults in vapor compression air conditioners, International Journal of Refrigeration, Vol. 30(3), 546-564.

Li, H. and Braun, J.E., 2008, A method for modeling adjustable throat-area expansion valves using manufacturers' rating data, $H V A C \& R$ Research, Vol. 14(4), 581-598.

Messenger, M., 2008, Strategic Plan to Reduce the Energy Impact of Air Conditioners, California Energy Commission Staff Report (CEC-400-2008-010).

Navarro-Esbri J., Berbegall V., Verdu G., Cabello R., and Llopis R., 2007, A low data requirement model of a variable speed vapor compression refrigeration system based on neural networks, International Journal of Refrigeration, Vol.30(8), 1452-1459.

Park, C., Cho, H. and Kim, Y., 2007, Mass flow characteristics and empirical modeling of R22 and R410A flowing through electronic expansion valves, International Journal of Refrigeration, Vol.30(80), 1401-1407.

Park Y.C., Kim Y.C., and Min M.K., 2001, Performance analysis on a multi-type inverter air conditioner, Energy Conversion and Management, Vol.42(13), 1607-1621.

Qureshi T.Q. and Tassou S.A., 1996, Variable speed capacity controls in refrigeration system, Applied Thermal Engineering, Vol.16(2), 103-113.

Rossi, T. M. and Braun, J. E., 1997, A Statistical, Rule-Based Fault Detection and Diagnostic Method for Vapor Compression Air Conditioners, HVAC\&R Research, Vol. 3(1), 19-37.

Shanwei, M., Chuan, Z., Jiangping, C., and Zhiujiu, C., 2005, Experimental research on refrigerant mass flow coefficient of electronic expansion valve, Applied Thermal Engineering., Vol. 25(14), 23512366. 


\section{Figure Captions}

Figure 1. Volumetric flow rate ratio in terms of evaporator saturation temperature for different compressor speeds (system I) 8

Figure 2. Performance of VRMF sensor based on fixed speed compressor map for system III under no fault and fault conditions (RMS of sensor errors shown for each fault type) 9

Figure 3. Performance of VRMF sensor based on variable speed compressor map for system I under no fault and fault conditions (RMS of sensor errors shown for each fault type) ....................................... 9

Figure 4. Performance of VRMF sensor II based on energy balance for system III under no fault and fault conditions (RMS of errors shown for each fault type)

Figure 5. Performance of VRMF sensor II based on energy balance for system I under no fault and fault conditions (RMS of errors shown for each fault type)...................................................................... 11

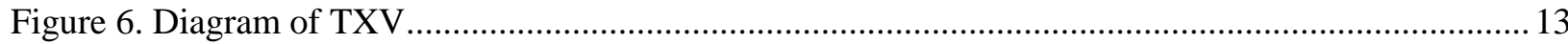

Figure 7. Performance of VRMF sensor III based on TXV for system III under no fault and fault conditions (RMS of sensor errors shown for each fault type) …........................................................ 15

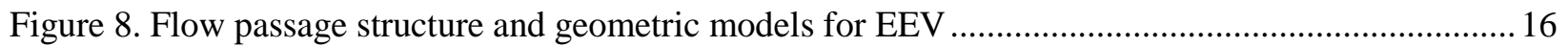

Figure 9 Performance of VRMF sensor III based on EEV for system I under no fault and fault conditions (RMS of sensor errors shown for each fault type) .............................................................................. 17

Figure 10. Performance of VRMF sensor III based on EEV with R-410A as refrigerant for system II..... 18

Figure 11. Performance of VRMF sensor III based on EEV with R-404A as refrigerant for system II..... 18

Figure 12. Comparison of VRMF sensor outputs for system III with compressor flow fault ................... 19

Figure 13. Comparison of VRMF sensor outputs for system I with compressor flow fault ..................... 19

Figure 14. Comparison of VRMF sensor outputs for system II (R410A) with compressor flow fault ......20

Figure 15. Comparison of VRMF sensor outputs for system II (R404A) with compressor flow fault ...... 20

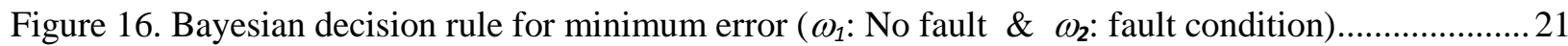

Figure 17. Flowcart for fault detection and diagnosis based on three VRM sensors................................22 


\section{Table Captions}

Table 1 System descriptions for laboratory test data ..........................................................................

Table 2 Test conditions for laboratory testing data............................................................................

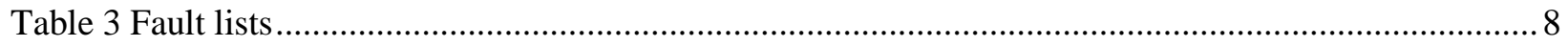

Table 4 Calculation of threshold for Bayesian classifier based on normal data for VRMF outputs...........24

Table 5 FDD responses of VRMF sensors to compressor valve leakage based on Bayesian classifier ....24

Table 6 FDD responses of VRMF sensors to 1) low refrigerant charge, 2) condenser fouling, and 3) liquid

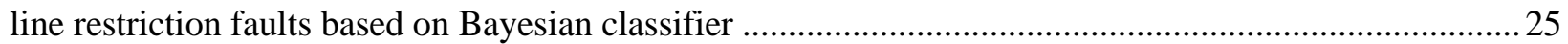

